\title{
Banka Kârlılığını Etkileyen Faktörler: Avrupa Birliği Bankaları ve Türk Bankaları Arasında Bir Karşılaştırma
}

\author{
Füsun KÜÇÜKBAY*
}

$\ddot{O} Z$

Çalışmada Türk bankalarının banka kârlıllğıın etkileyen faktörlerin panel veri analizi yardımı ile araştırılması amaçlanmıştır. Araştırma dönemi 2009-2013 yılları arasıdır. Çalışmada banka kârlılı̆̆ı bă̆ımlı değiş̧keni, banka kârlılı̆̆ını etkileyen faktörler bă̆ımsız değişkenleri oluşturmaktadır. Çalışmanın sonunda Türk bankacılık sektöründe kârlılı̆̆ı etkileyen faktörler Avrupa Birliği (AB) bankacılık sektöründe kârlılığı etkileyen faktörler ile karşılaştırılmıştır.

Türk bankalarının aktif kârlılı̆̆ını sermaye oranı ve banka büyüklügünün etkilediği; net faiz marjı değişkenini ise kredi oranı ve sermaye oranının etkilediği bulunmuştur. Avrupa Birliği'ne üye olan ülke bankalarında ise aktif kârlılı̆̆ını banka büyüklüğ̈̈, sermaye oranı, kredi oranı ve mevduat oranının etkilediği, net faiz marjını banka büyüklü̆̆̈̈, sermaye oranı, kredi oranı ve kredi kayıp karşılı̆̆ı oranının etkilediği görülmüşü̈r.

Anahtar Kelimeler: Banka kârlıllğğ, Avrupa Birliği bankacılık sektörü, Türk bankactlık sektörü, panel veri analizi

JEL Sinıflandırması: C23, G21, L25

\section{The Factors That Affect Bank Profitability: Comparison Between European Union Banks and Turkish Banks}

\begin{abstract}
In the study it is aimed to analyze the factors that affect the banks' profitability with the help of panel data analysis. The observation period is 2009-2013. In the study bank profitability is dependent variable and the factors that affect banks' profitability are independent variables. In the end of the study the factors affecting the Turkish banks' profitability and the factors affecting the European Union banks' profitability are compared.

The study revealed that the capital ratio and bank size affect the return of asset ratio of Turkish banks and loan ratio and the capital size affect the net interest margin ratio of Turkish banks. It is observed that the bank size, capital ratio, loan ratio and deposit ratio affect the return on asset ratio of European Union banks and bank size, capital ratio, loan ratio and loan loss provisions ratio affect the net interest margin ratio of European Union banks.
\end{abstract}

Key Words: Bank profitability, profitability, European Union banking sector, Turk banking sector, panel data analysis

JEL Classification: C23, G21, L25

\section{GİRIŞ}

Bankalar ülke ekonomilerinde çok önemli bir yere sahiptir ve ekonominin sağlıklı bir şekilde yürümesi için bazı temel görevleri üstlenmişlerdir. Bu temel görevleri; finansal aracılık etmek, likidite sağlamak, fon birikimi sağlayarak

\footnotetext{
* Yrd.Doç.Dr. Manisa Celal Bayar Üniversitesi İşletme Fakültesi, Ekonomi ve Finans Bölümü. Füsun.kucukbay@cbu.edu.t
} 
yatırımların finansmanına destek olmak, kısa vadeli kaynakların uzun vadeli yatırımlarda kullanılmasına yardımcı olarak vade uyumunu sağlamak, para politikalarının etkinliğini sağlamak ve çeşitli ödeme ve kredi seçenekleri sunarak ulusal ve uluslararası ticaretin gelişmesini sağlamak olarak sayabiliriz (Küçükbay, 2016: 13). Bu önemli görevleri nedeni ile bankaların sağlıklı bir yapıya sahip olması ekonominin etkin bir şekilde faaliyetlerine devam edebilmesi için çok önemlidir. Bankaların sağlıklı bir yapıya sahip olması ise ancak bankaların kârlılığının iyileştirilebilmesi ile mümkündür. Sonuç olarak bankaların kârlı olması mikro boyutta bankaların etkin bir şekilde faaliyetlerine devam edebilmesi için makro boyutta finansal sistemde istikrarın sağlanması için çok önemlidir.

Bu çalışmada banka kârlılığını etkileyen önemli faktörler tanımlanmaya çalışılmıştır. Çalışmada ilk önce Türk bankalarının kârlılı̆̆ını etkileyen faktörler panel veri analizinden yararlanılarak araştırılmıştır. Daha sonra çıkan sonuçlar Avrupa bankalarının kârlılı̆̆ını etkileyen faktörler ile karşılaştırılmıştır.

Kârlılık terimi bir işletmenin y1llar içerisinde kâr edebilme yeteneğini koruyabilmesidir. Bankaların da faaliyetlerine devam edebilmesi için kârlılık çok önemlidir. Sistemik risk kavramından yola çıkarak diyebiliriz ki bir bankanın kârlılığı, başarısızlığı ve riski tüm finansal sistemi etkileme potansiyeline sahiptir. Bu nedenle banka kârlılığının belirleyicileri literatürde hem teorik hem de ampirik olarak sıkça araştırılmıştır. Yapılan çalışmaların bazıları bir ülke üzerine yoğunlaşırken, bazıları ise ülke gruplarını kapsamaktadır. Tek ülke üzerine yapılan çalışmalara örnek olarak şu çalışmalar sayılabilir; Berger (1995), Angboza (1997), Gelos (2006) Amerika'daki bankaların kârlılı̆̆ının belirleyicilerini araştırmışlardır. Mamatzakis (2003), Athanasoğlu (2006) ve Alexiou ve Sofoklis (2009) Yunanistan'daki bankaların kârlılığının belirleyicileri üzerine çalışmışlardır. Javaid (2011), Saira vd. (2011) Pakistan bankaları, Lui ve Wilson (2010) ve Mosserinia v.d. (2014) Japon bankaları ve Kaya (2002), Güngör (2007), Gülhan ve Uzunlar (2011) ve Saldanlı ve Aydın (2016) Türk bankalarının kârlılığını etkileyen faktörleri araştırmışlardır.

Banka kârlılı̆̆ını etkileyen faktörleri ülke grupları bazında inceleyen çalışmalara örnek olarak verilebilecek çalışmalar şunlardır; Flamini vd. (2009) Sahra Altı Afrika ülkelerinde faaliyet gösteren bankaların kârlılığını etkileyen faktörleri incelemişlerdir. Hassan ve Bashir (2005) 21 farklı ülkedeki belli başlı İslami bankanın kârlılık belirleyicilerini araştırmışlardır. Molyneux (1992), Demirgüç ve Huizinga (1999), Saunder (2000), Pasiouras, Kosmidou (2007), Andries ve Ursu (2016) ve Menicucci ve Paolucci (2016) çalışmalarında Avrupa ülkelerinde faaliyet gösteren bankaların kârlılık belirleyicileri üzerine araştırma yapmışlardır.

Bununla birlikte, literatürdeki çalışmaların büyük çoğunluğunda, önemli bir çaba banka kârlılığı ile birden çok bağımsız değişken arasındaki ilişkiyi açıklamaya harcanmıştır. Daha önce yapılan çalışmalarda eğer banka ölçek ekonomisini iyi bir şekilde uygulayabilirse banka büyüklüğü ve banka kârlılığ1 arasında pozitif bir ilişkinin olacağını vurgulamaktadır. Ancak çeşitlenmenin artması banka riskinin de artmasına neden olmaktadır. Ayrıca bankalar 
büyüdükçe ölçek ekonomisini deneyimlemekle birlikte verimsizliklerle de karş1 karşıya kalmaktadırlar. Örneğin Humphrey(1997) ve Scholtens (2000) çalışmalarında küçük bankaların verimlilik artışı sağlayarak büyük bankalara göre daha kârlı olduklarını savunmaktadırlar. Bizim çalışmamızla uyumlu olarak banka büyüklüğü ve banka kârlılığı arasında negatif ilişki bulan çalışmalara Pasiouras ve Kosmidou (2007), Athanasoğlu v.d. (2008), Kosmidau (2008) ve Dietrich ve Wanzenried (2009) örnek verilebilir.

Banka büyüklüğünün banka kârlılığına negatif etki etmesinin nedeni; büyük bankaların ölçek ekonomisinden sağladıkları az bir maliyet avantajının verimsiz süreçlerini karşılayamaması nedeni ile kârın negatif etkilenmesi ya da büyük bankaların sabit maliyetlerinin, temsilcilik giderlerinin daha yüksek olması ve bürokratik süreçlerin fazla olmasından kaynaklanabilmektedir.

Banka büyüklüğünün banka karlılığına pozitif etki sağlayabilmesi, bankaların optimum büyüklüğe kavuşması ile mümkün gözükmektedir (Cihangir, 2005).

Bazı çalışmalarda ise banka sermaye oranının banka kârlılığını en fazla etkileyen bağımsız değişken olduğu vurgusu yapılmıştır. Kârlılık ve sermaye oranı arasındaki pozitif ilişki sağlıklı bir sermaye yapısına sahip bir bankanın daha yüksek oranda kâr elde edeceği anlamına gelmektedir. Bunun nedeni sermayesi güçlü bir bankanın daha uygun maliyetli fon sağlayabilmesi ve iflas etme riskinin düşük olmasından kaynaklanmaktadır. Düşük sermaye oranına sahip bir banka yüksek kaldıraca sahip olduğundan yüksek riske sahip olacaktır. Dolayısıyla fonlama maliyetleri yükselecek ve kârı olumsuz etkilenecektir. Banka kârlılığı ve sermaye oranı arasında pozitif ilişki bulan çalışmalara Molyneux ve Thornton (1992), Demirguç-Kunt ve Huizinga (1999), Hassan ve Bashir (2005), Pasiouras ve Kosmidou (2007) ve Menicucci ve Paolucci (2016) örnek verilebilir.

Bu çalışmada ise önce ülke bazında (Türkiye) banka kârlılığını etkileyen faktörler, panel veri analizinden yararlanılarak incelenmiş daha sonrasında ise Menicucci ve Paolucci (2016) nın Avrupa mevduat bankalarının kârlılığını etkileyen faktörleri inceledikleri çalışmanın sonuçlarından yararlanarak Türk bankalarının ve AB bankalarının kârlılığını belirleyen faktörler karşılaştırılmıştır. Sonuç olarak bu çalışma literatüre hem Türk bankalarının kârlılığını etkileyen faktörlerin belirlenmesi ile hem de Türk ve AB bankalarının kârlılığını etkileyen faktörlerin karşılaştırılması ile katkı sağlayacaktır.

Çalışmanın ikinci bölümünde araştırmanın yöntemi, değişkenleri, örneklem ve veri seti anlatılmıştır. Üçüncü bölümde Türkiye'de faaliyet gösteren mevduat bankalarının kârlılı̆̆ını etkileyen faktörlerin araştırıldığı çalışmanın sonuçları mevcuttur. Dördüncü bölümde $\mathrm{AB}$ bankalarının kârlılığını etkileyen faktörler ile Türk bankalarının kârlılığını etkileyen faktörler karşılaştırılmıştır. Çalışma, sonuçların değerlendirilmesi ve özetlenmesi ile sonuçlandırılmıştır. 


\section{VERİ, DEĞİŞKENLER VE METODOLOJİ}

Çalışmanın bu bölümünde çalışmanın örneklemi, araştırmada kullanılacak yöntem ve değişkenler anlatılacaktır.

\section{A. Örneklem ve Veri Seti}

Araştırmanın örneklemi Türkiye'de faaliyet gösteren mevduat bankalarıdır. Çalışmada mevduat bankalarının kârını etkileyen faktörler analiz edilmeye çalışılacaktır. Ayrıca Türk bankaları ve $\mathrm{AB}$ bankalarının kârlılık belirleyicileri arasında bir farklılık olup olmadığı incelenmeye çalışılacaktır. Çalışmanın çıktılarının Menicucci ve Paolucci (2016) nin çalışması ile karşılaştırılabilmesi adına çalışma dönemi 2009-2013 yıllarını kapsamaktadır. Bu dönem içerisinde yeterli analiz verisine sahip 28 Türk mevduat bankası çalışmanın örneklemini oluşturmaktadır.

Araştırmada kullanılacak bağımlı ve bağımsız değişkenler Türkiye Bankalar Birliğinin internet sayfasındaki istatistiki raporlarlar bölümünden elde edilmiş ve hesaplanmıştır.

\section{B. Araştırma Yöntemi ve Modelde Kullanılacak Değişkenler}

Araştırmanın dördüncü bölümünde Menicucci ve Paolucci (2016) nin yaptığı çalışma sonuçları ile karşılaştırma yapılacağından dolayı araştırmada kullanılan değişkenler ve gözlem periyodu bu çalışma ile aynı seçilmiştir. Daha önce bahsedildiği gibi gözlem periyodu 2009-2013 dönemidir. Tablo 1'de çalışmada kullanılan bağımlı ve bağımsız değişkenler, bu değişkenler için kullanılan kısaltmalar ve bu değişkenlerin nasıl hesaplandığı gösterilmiştir. Banka kârlılığı iki farklı bağımlı değişken kullanarak iki farklı modelle araştırılmıştır. Seçilen bağımlı değişkenler aktif kârlılığı ve net faiz marjıdır. Bağımsız değişkenler ise her iki modelde de aynıdır ve banka büyüklüğü, sermaye oranı, kredi oranı, mevduat oranı ve kredi kayıp karşılığı oranıdır.

Tablo 1: Çalışmada Kullanılan Değişkenler

\begin{tabular}{|l|l|l|}
\hline Değişken & Kısaltma & Açıllama \\
\hline Bağımlı Değişkenler & & Net Kâr/Aktif Toplamı \\
\hline Aktif Kârlılı̆̆ı & AK & Net Faiz Geliri/Aktif Toplamı \\
\hline Net Faiz Marjı & NFM & Aktif Toplamı (milyon TL) \\
\hline Bağımsız Değişkenler & & Özkaynak/Aktif Toplamı \\
\hline Banka Büyüklüğü & B & Kredi ve Alacaklar/Aktif Toplamı \\
\hline Sermaye Oranı & SRM & Toplam Mevduatlar/Aktif Toplamı \\
\hline Kredi Oranı & KRD & $\begin{array}{c}\text { Özel Karşllılar/Toplam Kredi ve } \\
\text { Mevduat Oranı }\end{array}$ \\
\hline $\begin{array}{c}\text { Kredi Kayıp Karşıllı̆̆ı } \\
\text { Oranı }\end{array}$ & KK & Alacaklar \\
\hline
\end{tabular}

Çalışmada veri setinin analiz edilmesinde panel veri analizinin uygunluğu $\mathrm{F}$ testi yapılarak test edilmiştir. Çalışmada iki farklı bağımlı değişken olduğu için iki farklı model kullanılmıştır. Model 1 ve model 2 için yapılan F testinin olasılık değerleri 0,0000 çıkmıştır. Bu durum \%99 güven düzeyinde araştırma verilerinin panel veri analizi için uygun olduğunu göstermiştir. Sonuç olarak çalışmada 
bankaların kârlılığını etkileyen faktörlerin analizi için Menicucci ve Paolucci (2016) çalışmasına benzer olarak panel veri analizinden yararlanılmıştır.

Çalışmada verilerin hem bankalara hem de zamana göre değiş̧iklik göstereceği düşünülmüştür. Panel veri analizinin yatay kesit analizi ile zaman serisi analizini birleştiren bir analiz yöntemi olması sebebi ile kullanılması tercih edilmiştir. Panel veri analizinde zaman kesiti 2009 ile 2013 dönemi, yatay kesitse bankalar olarak alınmıştır.

$\mathrm{Bu}$ çalışmada iki temel panel regresyon modeli oluşturulmuştur.

$$
\begin{gathered}
\mathrm{AK}_{\mathrm{it}}=\beta_{\mathrm{i}}+\beta_{1} B_{\mathrm{it}}+\beta_{2} \mathrm{SRM}_{\mathrm{it}}+\beta_{3} \mathrm{KRD}_{\mathrm{it}}+\beta_{4} \mathrm{MVD}_{\mathrm{it}}+\beta_{5} \mathrm{KK}_{\mathrm{it}}+\mathrm{u}_{\mathrm{it}} \\
\mathrm{NFM}_{\mathrm{it}}=\beta_{\mathrm{i}}+\beta_{1} \mathrm{~B}_{\mathrm{it}}+\beta_{2} \mathrm{SRM}_{\mathrm{it}}+\beta_{3} \mathrm{KRD}_{\mathrm{it}}+\beta_{4} \mathrm{MVD}_{\mathrm{it}}+\beta_{5} \mathrm{KK}_{\mathrm{it}}+\mathrm{u}_{\mathrm{it}}
\end{gathered}
$$

Burada $\mathrm{i}$ indisi 1,2,3,4 ..., 28 şeklinde banka sayısını, $\mathrm{t}$ indisi 2009, 2010, ...,2013 şeklinde zaman aralığını göstermektedir. u hata terimini ifade etmektedir. Yukarıda yazılan eşitlik 1 model 1'e; eşitlik 2 model 2'ye karşl1ık gelmektedir. Panel veri modellerinde hata teriminin ortalamasının sifir, tüm zaman dönemlerinde ve tüm birimler için bağımsız ve varyansının normal dağıldığı kabul edilir. Panel veri çalışmalarında seriler arasında yatay kesit bağımlılı̆̆ varsa yapılan analizler bu bilgi ışığında yorumlanmalıdır. $\mathrm{Bu}$ nedenle analize başlamadan önce serilerde yatay kesit bağımlılığının varlığı test edilmelidir. (Yıldırım vd., 2013).

$\mathrm{Bu}$ çalışmada seriler arasında yatay kesit bağımlılığı; zaman boyutu (yıllar) yatay kesit (bankalar) boyutundan küçük olduğu için Pesaran (2004) CDLM testi ile kontrol edilmiştir. Yapılan test sonucunda, "Yatay kesit bağımlılığı yoktur" Ho hipotezi test sonucunda elde edilen olasılık değeri 0.05 den büyük olduğu için kabul edilmiştir. Bu sonuç paneli oluşturan bankaların bağımsız olduğu ve bankalardan birine gelen şoktan tüm diğer bankaların aynı düzeyde etkilendikleri anlaşılmaktadır.

Panel veri analizinde literatürde farklı modeller kullanılmaktadır. $\mathrm{Bu}$ modeller arasında en çok kullanılanlar; sabit etkiler modeli ve tesadüfi etkiler modelidir. Sabit etkiler modeli eğim katsayılarının zaman ve kesit birimleri için aynı olduğu, bunun yanında sabit katsayının yatay kesit birimlerine göre farklılık gösterdiği durumlarda kullanılırken; Tesadüfi etkiler modellerinde birimlere veya zamana göre meydana gelen değişiklikler hata teriminin bir bileşeni olarak modelde yer alırlar (Keskin ve Gökalp, 2016).

Literatürde sabit etki modeli ile tesadüfi etkiler modeli arasında bir tercih yapılması gerektiğinde kullanılan istatistiki yöntemler bulunmakla birlikte, en çok tercih edilen test istatistiği Hausman test istatistiğidir. Hausman test istatistiği tesadüfi etkiler ve sabit etkiler modellerinde bulunan katsayıların benzerliğini test eder. Hausman test istatistiğine ait $\mathrm{p}>0,05$ çıkması durumunda tesadüfi etkiler tahmincisinin geçerli olduğu sonucuna varılırken, $\mathrm{P}<0,05$ çıkması durumunda ise sabit etkiler tahmincisinin geçerli olduğu sonucuna varılır.

\section{ANALIZ SONUÇLARI}

Bu bölümde tanımlayıcı istatistikler, ve panel veri analizi sonuçlarına yer verilmiştir. Çalışmanın analizlerinde Stata 14 programından yararlanılmıştır. 


\section{A. Tanımlayıcı Analizler}

Tablo 2'de regresyon modelinde kullanılan bağımlı ve bağımsız değişkenlere ilişkin tanımlayıcı istatistiklere yer verilmiştir.

Tablo 2: Tanımlayıc İstatistikler

\begin{tabular}{|c|c|c|c|c|}
\hline Değișkenler & Ortalama & Std. Sapma & Minimum & Maksimum \\
\hline \multicolumn{5}{|l|}{ Bă̆ımlı } \\
\hline AK & 1.7344 & 1.8994 & -4.5682 & 11.3340 \\
\hline NFM & 4.3876 & 3.1420 & 0.8517 & 26.5864 \\
\hline \multicolumn{5}{|l|}{$\begin{array}{l}\text { Băğtmsız } \\
\text { Değişkenler }\end{array}$} \\
\hline KRD & 51.1217 & 20.4655 & 0 & 84.7161 \\
\hline SRM & 17.2759 & 14.3562 & 4.4413 & 92.4850 \\
\hline MVD & 56.2801 & 18.3898 & 2.7042 & 87.3467 \\
\hline KK & 3.7042 & 3.9786 & 0 & 23.6098 \\
\hline B & 39866.865 & 56448.504 & 73.0250 & 210.500 .04 \\
\hline
\end{tabular}

Tanımlayıcı istatistikler bağımlı ve bağımsız değişkenlerin ortalama, minimum, maksimum ve standart sapma değerlerini göstermektedir. Tablodan görüldüğü gibi Türk mevduat bankalarının 2009-2013 dönemi içerisinde ortalama aktif kârlılığ 1.7344 'dir. Aktif kârlılı̆̆ $-4,5682$ ile 11.3340 aralığında değişmektedir. Bankaların net faiz marjı değerlerinin ortalaması 4,3876'dir. Net faiz marj1 da 0,8517 ve 26,5864 aralığında değişmektedir. NFM ve AK değerlerinin standart sapması sırası ile 1,899467 ile 3,1420396 çıkmıştır.

Bağımsız değişkenler, KK değişkeni dışında çok yüksek oranda standart sapmaya sahiptir minimum ve maksimum değerleri de büyük değişiklik göstermektedir. Özellikle bankaların büyüklüğü en yüksek standart sapmaya sahiptir. Bunun nedeni örneklemde mevcut olan bankaların farklı büyüklüğe buna bağlı olarak da farklı kredi ve mevduat hacmine sahip olmasına bağlıdır.

\section{B. Panel Regresyon Analizi Sonuçları}

Araştırmada AK ve NFM bağımlı değişkenleri oluşturmaktadır. İki farklı bağımlı değişken olduğu için iki farklı regresyon modeli oluşturulmuştur.

Model 1, Türkiye'de faaliyette bulunan mevduat bankalarının kârlılık belirleyicilerini belirlemek için oluşturulmuştur. Bağımlı değişken $\mathrm{AK}$ ve bağımsız değişkenler B, SRM, KRD, MVD ve KK'dır.

Tablo 3'de model 1 için yapılan sabit etkiler tahmin sonuçları ve Hausmann test istatistiği sonucu görülmektedir. .

Panel veri analizinde sabit etki modeli ile tesadüfi etkiler modeli arasında tercih yapabilmek için Hausman test istatistiği kullanılmış ve Hausman test istatistiğinde $\mathrm{P}<0,05$ çıkması nedeni sabit etkiler tahmincisinin geçerli olduğu sonucuna ulaşı1mış̧ır.

Model 1'de bağımlı değişken AK bağımsız değişkenler SRM, KRD, MVD, KK ve B'dir. Aktif kârlılığı ile SRM arasında \%99 güven aralığında ve banka büyüklüğü banka aktif kârlılığı arasında $\% 90$ güven aralığında istatistiksel olarak anlamlı bir ilişki bulunmuştur. Aktif kârlılığı ile SRM arasında pozitif bir 
ilişki mevcut iken aktif kârlılı̆ğ ve banka büyüklüğü arasında negatif bir ilişki tespit edilmiştir

Model 1'in sabit etkiler tahmin modelinde KRD, MVD ve KK değişkenleri ile banka aktif kârı arasındaki ilişki istatistiki olarak anlamsız çıkmıştır.

Tablo 3: Model 1 İçin Sabit Etkiler Modelleri Tahmin Sonuçları

\begin{tabular}{|c|c|c|c|}
\hline \multicolumn{4}{|c|}{ Bağımlı Değişken: AK } \\
\hline & Katsayı & $t$-değeri & $p$-de ğeri \\
\hline Sabit & 1.0260 & 0.94 & 0.350 \\
\hline KRD & 0.0020 & 5.08 & 0.862 \\
\hline SRM & 0.0902 & 6.08 & 0.000 \\
\hline MVD & -0.0094 & -0.83 & 0.409 \\
\hline KK & 0.0778 & 0.13 & 0.899 \\
\hline B & $-1.67 e-07$ & -1.77 & 0.079 \\
\hline Haussman Test İstatistiği & & & 0.0115 \\
\hline
\end{tabular}

Araştırmanın sonuçları banka büyüklügünün aktif kârl1lı̆̆ üzerinde negatif bir etkisinin olduğunu göstermektedir. Model 2'nin sonuçlarında da istatistiki olarak anlamlı olmasa da banka büyüklüğü ve NFM arasında negatif bir ilişkinin mevcut olduğu tablo 4'de görülmektedir. Bu durum Türkiye'de küçük bankaların büyük bankalara göre daha fazla aktif kârlılığı ve net faiz marjı sağladıklarını göstermektedir. Bu sonuç literatürde vurgulanan sonuçlarla uyum göstermektedir. (Humphrey(1997), Scholtens (2000), Pasiouras ve Kosmidou (2007), Athanasoğlu v.d. (2008), Kosmidau (2008), Dietrich ve Wanzenried (2009)).

Tablo 3 ve Tablo 4'den görüldügü gibi banka sermaye oranı, hem AK hem de NFM oranını \%99 güven aralığında pozitif yönde etkilemektedir. T değeri en yüksek bağımsız değiş̧en sermaye oranıdır. Bu sonuçlar banka kârlılığı ve sermaye oranı arasında pozitif ilişki bulan çalışmalarla uyum göstermektedir (Molyneux ve Thornton (1992), Demirguç-Kunt ve Huizinga (1999), Hassan ve Bashir (2005), Pasiouras ve Kosmidou (2007) ve Menicucci ve Paolucci (2016)).

Model 2 de bağımlı değişken net faiz marjı oranı ve bağımsız değişkenler B, SRM, KRD, MVD ve KK oranlarıdır. Model 2 için yapılan Hausman test istatistiğinin sonucunda $\mathrm{P}<0,05$ çıkması nedeni ile sabit etkiler tahmincisinin geçerli olduğu sonucuna ulaşılmıştır. Hausman test istatistiğinin sonuçları ve model 2 için yapılan sabit etkiler modeli tahmin sonuçları tablo 4'de görülmektedir.

Model 2'de bağımlı değişken NFM bağımsız değişkenler SRM, KRD, MVD, KK ve B'dir. NFM ile SRM arasında ve kredi oranı ile NFM arasında \%99 güven aralığında istatistiki olarak anlamlı bir ilişki bulunmuştur. NFM ile SRM arasında ve NFM ile KRD arasında pozitif bir ilişki mevcuttur. 
Tablo 4: Model 2 İçin Sabit Etkiler Modelleri Tahmin Sonuçları

\begin{tabular}{|l|l|l|l|}
\hline \multicolumn{3}{|c|}{ Bağımlı Değişken: NFM } \\
\hline & Katsayı & $t$-değeri & $p$-değeri \\
\hline Sabit & -3.1016 & -1.52 & 0.130 \\
\hline KRD & 0.6526 & 2.94 & $\mathbf{0 . 0 0 4}$ \\
\hline SRM & 0.1814 & 6.56 & $\mathbf{0 . 0 0 0}$ \\
\hline MVD & 0.2123 & 1.27 & 0.207 \\
\hline KK & 0.0509 & 0.45 & 0.657 \\
\hline B & $-2.12 \mathrm{e}-08$ & -1.44 & 0.130 \\
\hline Hausmann Test İstatistiği & & & $\mathbf{0 . 0 0 1 1}$ \\
\hline
\end{tabular}

$R^{2}=0.3830 \quad F$-istatistiği $=13.28 \quad$ p-de $\breve{g} \operatorname{eri}(F)=0.0000$

Model 2'nin sabit etkiler tahmin modelinde B, MVD ve KK değişkenleri ile banka net faiz marjı oranı arasında istatistiki olarak anlamlı bir ilişki bulunamamıştır.

Bankaların verdikleri kredi oranının artması ile bankaların net faiz marjı oranı artış göstermektedir. Bu durum bankaların aracılık görevini üstlenmeleri ile açıklanabilir. Bankalar topladıkları mevduat ve fonları ne kadar çok kredi olarak verirse gelirleri o düzeyde artacaktır. Bankaların aktif kârlılığı ve kredi oranı arasında her ne kadar istatistiki olarak anlamlı bir ilişki bulunmasa da aralarındaki ilişki NFM ve kredi oranı arasındaki ilişki gibi pozitif yönlüdür. $\mathrm{Bu}$ sonuç Menicucci ve Paolucci (2016) çalışması ile uyumlu çıkmıştır.

\section{TÜRK BANKALARININ KÂRLILIK BELIRLEYİCILERİ İLE AVRUPA BİRLİĞİ BANKALARININ KÂRLILIK BELİRLEYICILERİ ARASINDA BİR KARŞILAŞTIRMA}

$\mathrm{Bu}$ bölümde Türk bankalarının kârlılık belirleyicileri ile AB ülkelerinin banka kârlılık belirleyicileri arasında bir karşılaştırma yapılacaktır. Türk bankalarının kârlılık belirleyicilerine ait veriler bu çalışmanın üçüncü bölümdeki sonuçlardan yararlanılarak elde edilmiştir. AB üye ülkelerin banka kârlılığının belirleyicileri ile ilgili veriler Menicucci ve Paolucci (2016) çalışmasından yararlanarak elde edilmiştir.

Menicucci ve Paolucci (2016) çalışmalarında 2009-2013 dönemi için 35 Avrupa mevduat bankasının karlilık belirleyicilerini panel veri analizinden yararlanarak belirlemişlerdir.

Tablo 5'de hem Türk hem de Avrupa bankalarının aktif kârlılığı belirleyicileri için oluşturulan sabit etkiler tahmin modellerinin sonuçları görülmektedir. Avrupa bankalarının banka büyüklüğü (\%95 güven düzeyi), sermaye oranı (\%99 güven düzeyi), kredi oranı (\%90 güven düzeyi) ve mevduat oranı (\%99 güven düzeyi) bankaların aktif kârlılığını istatistiki olarak anlamlı etkilerken, Türk bankalarının sadece sermaye oranı (\%99 güven düzeyi) ve banka büyüklüğü (\%90 güven düzeyi) bankaların aktif kârlılığını istatistiki olarak etkilemektedir.

İstatistiki olarak anlamlı olarak bulunan değişkenlerde farklılık olmasının dışında banka büyüklüğünün aktif kârlılığını etkileme yönü de farklılık 
göstermektedir. Avrupa bankalarında banka büyüklüğü hem aktif kârlılığını hem de net faiz marjını pozitif yönde etkilediği bulunurken Türk bankaların banka büyüklüğü aktif kârlılığını ve net faiz marjını negatif yönde etkilediği bulunmuştur.

Tablo 5: Avrupa Birliği Bankaları ve Türk Bankaları İçin Yapılan Sabit Etkiler Modellerinin Karşılaştırmalı Tahmin Sonuçları (Bağımlı Değişken AK)

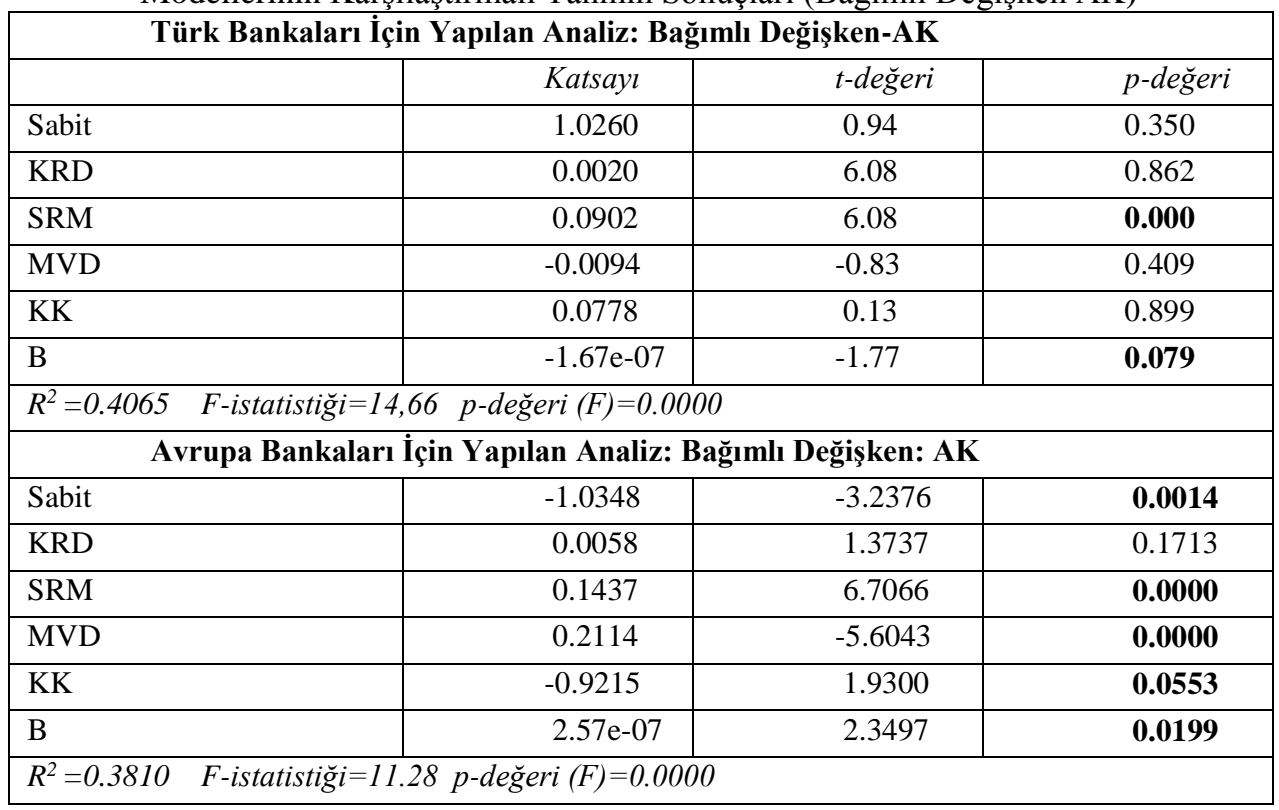

Bankalar optimum büyüklüğe ulaşmaları durumunda banka büyüklüğü ve banka karlılığı arasında pozitif bir ilişkinin olacağı çeşitli çalışmalarda vurgulanmıştır. Banka optimum büyüklüğe kavuşması durumunda personel giderleri, bilişim sistemlerinin birlikte kullanılması ve operasyon maliyetleri gibi sabit maliyetleri azaltılabilmekte böylece banka büyüklügü arttıkça banka karlılı̆g 1 yükselmektedir. Çalışmada yapılan karşılaştırma sonucunda $\mathrm{AB}$ bankalarının optimum banka büyüklüğünü sağlayabildiği ancak Türk bankalarının bunu sağlayamadığı yani bankaların büyüklüğü arttıkça banka karlılığının azaldığ görülmektedir. Bu durum Türkiye'deki büyük bankaların ölçek ekonomisinden yararlanamadıklarını düşündürmektedir. Bunun nedenleri büyük bankalarda verimsiz süreçlerin mevcut olması, sabit maliyetlerin, temsilcilik giderlerinin yüksek olması ve bürokrasinin fazla olmasından kaynaklanabilmektedir. Ayrıca Türkiye'de bankaların şube sayısını arttırmasının temel nedeni, Yakıcı ve Çankaya (2002) tarafından, maliyet avantajı sağlamak gibi ekonomik kaygılardan değil bankanın tanınırlı̆̆ının ve prestijinin arttırılmasının sağlanması gibi nedenler olarak açıklanmıştır.

Tablo 6'da hem Türk hem de Avrupa bankalarının net faiz marj1 belirleyicileri için yapılan sabit etkiler tahmin modellerinin sonuçları 
görülmektedir. Sonuçlarda, Türk bankaların kredi oranı ve sermaye oranının net faiz marjını istatistiki olarak anlamlı olarak etkilediği; Avrupa bankalarının ise çalışmaya dahil edilen mevduat oranı dışındaki tüm bağımsız değişkenlerin net faiz marjını etkilediği görülmektedir.

Tablo 6: Avrupa Birliği Bankaları ve Türk Bankaları İçin Yapılan Sabit Etkiler

Modellerinin Karşılaştırmalı Tahmin Sonuçları (Bağımlı Değişken NFM)

\begin{tabular}{|c|c|c|c|}
\hline \multicolumn{4}{|c|}{ Türk Bankaları Íçin Yapılan Analiz: Bağımlı Değişken- NFM } \\
\hline & Katsayı & t-değgeri & p-değeri \\
\hline Sabit & -3.1016 & -1.52 & 0.130 \\
\hline KRD & 0.6526 & 2.94 & 0.004 \\
\hline SRM & 0.1814 & 6.56 & 0.000 \\
\hline MVD & 0.2123 & 1.27 & 0.207 \\
\hline KK & 0.0509 & 0.45 & 0.657 \\
\hline $\mathrm{B}$ & $-2.12 \mathrm{e}-08$ & -1.44 & 0.130 \\
\hline \multicolumn{4}{|c|}{$R^{2}=0.3830 \quad F$-istatistiği $=13.28 \quad$ p-değeri $(F)=0.0000$} \\
\hline \multicolumn{4}{|c|}{ Avrupa Bankaları İçin Yapılan Analiz: Bağımlı Değişken: NFM } \\
\hline Sabit & -1.5991 & -7.3894 & 0.0000 \\
\hline KRD & 0.0165 & 5.7102 & $\mathbf{0 . 0 0 0 0}$ \\
\hline SRM & 0.1455 & 10.0334 & 0.0000 \\
\hline MVD & 0.0390 & 1.5289 & 0.1282 \\
\hline KK & -2.0725 & 6.4108 & 0.0000 \\
\hline B & $3.25 \mathrm{e}-07$ & 4.3767 & 0.0000 \\
\hline
\end{tabular}

Çalışma sonucunda hem $\mathrm{AB}$ bankalarında hem de Türk bankalarında banka sermaye oranının, banka kârlılığını en fazla etkileyen bağımsız değişken olduğu ortaya çıkmıştır. Hem AB bankaları hem de Türk bankaları için yüksek oranda öz sermayeye sahip olmanın bankaların karlılığını olumlu olarak etkilediği anlamına gelmektedir. Bunun nedeni sermayesi güçlü bir bankanın daha kolay ve ucuz fon bulma imkânına sahip olmasından kaynaklanabilmektedir. Fonlama maliyetleri ucuzlayan bankaların karlılık oranı yükselmektedir.

\section{SONUC}

Bankalar kâr etme amacı güden ve bu amaç doğrultusunda faaliyetlerine devam eden kuruluşlardır. Topladıkları fonları fon ihtiyacı kişilere aktaran ekonominin devamlılığını sağlayan ülke ekonomileri için önemli kuruluşlardır. Bankaların sağlıklı bir yapıya sahip olması için istikrarlı bir şekilde kâr elde edebilmesi gereklidir. $\mathrm{Bu}$ gereklilikten yola çıkarak çalışmada bankaların kârlılığını etkileyen faktörlerin analiz edilmesi amaçlanmıştır. Bu amacın dışında banka kârlılık belirleyicilerinin $\mathrm{AB}$ üye ülkeleri ile Türk bankaları arasında farklılık gösterip göstermediği araştırılmıştır.

Çalışma sonuçları banka büyüklüğü ve sermaye oranının hem $\mathrm{AB}$ hem de Türk bankalarının aktif kârlılı̆g üzerinde istatistiksel olarak anlamlı bir etkisi olduğunu göstermektedir. Burada en önemli fark, banka büyüklüğünün aktif 
kârlılı̆̆ını Avrupa'da pozitif Türkiye'de negatif olarak etkilemesidir. Avrupa bankalarında banka büyüklüğünün hem aktif kârlılığını hem de net faiz marjını pozitif yönde etkilediği bulunurken Türk bankalarında banka büyüklüğünün, aktif kârlılığını ve net faiz marjını negatif yönde etkilediği bulunmuştur. Bu durum Türkiye'deki büyük bankaların ölçek ekonomisinden yararlanamadıklarını göstermektedir. Bunun nedenleri ölçek ekonomisinden sağlanan faydanın verimsiz süreçlerden kaynaklı ve sabit maliyetlerin yüksekliğinden kaynaklı zararları karşılayamamasından kaynaklanabilmektedir.

Banka büyüklüğü ve sermaye oranı değişkenlerinin yanında kredi oranı ve mevduat oranı Avrupa bankalarında bankaların aktif kârlılığını istatistiki olarak etkilerken, Türk bankalarının aktif kârlılığını istatistiki olarak etkilememektedir.

Net faiz marjı ile ilgili model sonuçlarında ise Avrupa bankalarında mevduat oranı dışındaki diğer tüm değişkenler sonuç üzerinde istatistiksel olarak anlamlı bir etkiye sahipken, Türk bankalarında sadece kredi oranı ve sermaye oranının net faiz marjını istatistiki olarak anlamlı etkilediği görülmüştür.

Çalışma hem Türk bankalarının yüksek karlılık sağlaması için hangi banka içi faktörlerin etkili olduğunu bulmaya çalışmış hem de Türk bankalarının banka karlılığını belirleyen faktörler ile $\mathrm{AB}$ bankalarının karlılığını belirleyen faktörler arasında karşılaştırma yapmıştır. Çalışma sonuçlarının bankaların karlılığını arttırmak ve istikrarı sağlamak için hem bankalar hem de bankaları denetleyen kuruluşlar tarafından faydalı olacağı düşünülmektedir.

\section{KAYNAKÇA}

Andrieş, A.M., Ursu, S.G (2016), 'Financial crisis and bank efficiency: An empirical study of European banks', Economic Research-Ekonomska Istraživanja, Vol 29, No:1, 485-497.

Angbazo, L. (1997). "Commercial Banks, Net Interest Margins, Default Risk, Interest Rate Risk and Off-Balance Sheet Banking," Journal of banking and Finance, Vol.21, 55-87.

Alexiou, C., Sofoklis, V. (2009). 'Determinants of bank profitability: Evidence from the Greek Banking Sector', In: Ekonomski anali, Vol. 54 No.182, 93-118.

Athanasoglou P., Delis M. and C. Staikouras (2006). "Determinants of Banking Profitability in the South Eastern European Region," Bank of Greece Working Paper, 06/47.

Athanasoglou, P.P., Brissimis, S.N. and Delis, M.D. (2008), "Bank-specific, industry-specific and macroeconomic determinants of bank profitability", Journal of International Financial Markets, Institutions and Money, Vol. 18 No.2, 121-136.

Berger, A.N., (1995), 'The Profit-Structure Relationship in Banking-Tests of Market-Power and Efficient-Structure Hypotheses', Journal of Money, Credit, and Banking , Vol.27 No.2, 404-431.

Cihangir, M. (2005), Bankacılıkta Optimum Büyüklük : Türk Bankacılık Sektörü Üzerinde Ampirik Bir Çalışma, D.E.Ü.İ̈.B.F. Dergisi, Vol. 20 No.2, 11-26.

Demirgüç-Kunt, A., Huizinga, H., (1999), 'Determinants Of Commercial Bank Interest Margins And Profitability: Some International Evidence' The World Bank Economic Review, Vol. 13 No.2, 379-408.

Dietrich, A. and Wanzenried, G. (2009), "Determinants of Bank Profitability Before and During the Crisis: Evidence from Switzerland", Journal of International Financial Markets, Institutions and Money, Vol. 21 No.3, 307-327.

Flamini, V., Mcdonal C., Schumacher, L. (2009), 'The Determinants of Commercial Bank Profitability in Sub-Saharan Africa', IMF Working Paper, WP/09/15.

Gelos, G. (2006). "Banking Spreads in Latin America," IMF Working Paper, 06/44. 
Goddard, J.A., Molyneux, P. ve Wilson, J.O.S. (2004). "The Profitability of European Banks: A Cross-Sectional and Dynamic Panel Analysis". The Manchester School, Vol. 72 No.3, 363-381.

Gülhan, Ü., Uzunlar, E (2011)., 'Bankacılık Sektöründe Kârlılığı Etkileyen Faktörler: Türk Bankacılık Sektörüne Yönelik Bir Uygulama', Atatürk Üniversitesi Sosyal Bilimler Enstitüsü Dergisi, Cilt. 15 No.1, 341-368.

Hassan, M.K. and Bashir, A.M. (2005), "Determinants of Islamic Banking Profitability", Paper presented at the Economic Research Forum (ERF) 10th Annual Conference, Marrakech, Marocco, 16-18 December.

Kaya, Y.T.,(2002), 'Türk Bankacılık Sektöründe Kârlılığın Belirleyicileri 1997-2000', MSPD Çalışma Raporlarl, 2002/1.

Keskin, R., Gökalp, F. (2016) "Çalışma Sermaye Yönetiminin Firma Kârlılığı Üzerine Etkisi: Panel Veri Analizi”, Dogus University Journal, Cilt. 17 No.1, 15-25.

Kosmidou, K., Tanna, S. and Pasiouras, F. (2008), "Determinants of profitability of domestic UK commercial banks: panel evidence from the period 1995-2002", Economics, Finance and Accounting Applied Research, Working paper, Series No. RP08-4, Coventry: Coventry University, 1-27.

Küçükbay, F (2016), Bankalar ve Risk, Nobel Akademik Yayıncılık, İstanbul

Lui, H., Wilson, J. (2010), 'The Profitability of Banks in Japan', Applied Financial Economics Vol. 20 No. 24, 1851-1866.

Javaid, S., Anwar, J., Zaman, K., Gafoor, A., (2011), 'Determinants of Bank Profitability in Pakistan: Internal Factor Analysis', Mediterranean Journal of Social Sciences, Vol. 2 No.1, 59-78.

Mamatzakis, E. C., Remoundos, P. C. (2003), 'Determinants of Greek Commercial Banks Profitability, 1989 - 2000', Spoudal, Vol. 53 No.1, 84-94.

Massarini A., ArffM., Fan-Fah C. (2014), 'Key Determinants of Japanese Commercial Banks Performance', Pertanika J., Soc. Sci. \& Hum, Vol. 22, 17 - 38 .

Menicucci, E., Paolucci, G. (2016), 'The Determinants Of Bank Profitability: Empirical Evidence From European Banking Sector', Journal of Financial Reporting and Accounting, Vol. 14 No.1 $86-115$.

Molyneux, P., Thorton, J., (1992), 'Determinants of European Bank Profitability; A Note', Journal of Banking and Finance, Vol. 16, 1173-78.

Pasiouras F. and Kosmidou K. (2007), "Factors influencing the profitability of domestic and foreign banks in the European Union", Research in International Business and Finance, Vol.21 No.2, 222-237.

Pesaran, M. H. (2004), "General Diagnostic Tests for Cross Section Dependence in Panels", Cambridge Working Papers in Economics, 435.

Saldanlı, A., Aydın, M. (2016), "Bankacılık Sektöründe Kârlılığı Etkileyen Faktörlerin Panel Veri Analizi İle İncelenmesi : Türkiye Örneği”, İstanbul Üniversitesi İktisat Fakültesi Ekonometri ve İstatistik Dergisi, Cilt.24, 1-9.

Saunders, A. and L. Schumacher (2000). "The Determinants of Bank Interest Rate Margins: An International Study," Journal of International Money and Finance, Vol.19, 813-832.

Saira, J., Anwar, J., Khalid, Z. , Abdul, G. (2011), "Determinants of Bank Profitability in Pakistan: Internal Factor Analysis", Journal of Yasar University, Vol.23 No.6, 3794-3804.

Scholtens, B. (2000), "Competition, Growth and Performance in the Banking Industry", Department of Finance Working Paper, University of Groningen, Netherlands, February.

Yakıcı, T. A., Çankaya F. (2002), "Türk Bankacılık Sisteminin Ölçek Ekonomileri Açısından Değerlendirilmesi”, Bankacilar Dergisi, Cilt.43, 33-50.

Yıldırım, K., Mercan, M., Kostakoğlu, S.F. (2013). "Satın Alma Gücü Paritesinin Geçerliliğinin Test Edilmesi: Zaman Serisi ve Panel Veri Analizi”, Eskişehir Osmangazi Üniversitesi İibf Dergisi, Aralik 2013, 8(3), 75- 95. 


\section{SUMMARY}

Banks are the organizations which aim to make profit and perform their activities to achieve this purpose. Banks play a vital role for the sustainability of the economy in a country by assigning the funds. To act their roles successfully, banks must achieve sustainable profitability. In this study, it is aimed to investigate the factors which affect the profitability of the banks. Furthermore, this study also examines the differences between EU members and Turkey in terms of the factors of bank profitability.

The results of the study show that bank size and capital ratio have a statistically significant effect on the return on asset ratio of both EU and Turkish banks. The main difference between the results of the models of EU members and Turkey is that while the bank size positively affect the profitability in EU members, it negatively affect the profitability in Turkey. The results of the study also highlight that bank size has positive effects on the both net interest margin and return on assets ratio of the banks in EU. On the contrarily, the results also indicate that bank size has negative effects on both net interest margin and return on asset ratio of the banks in Turkey. It means that the banks in Turkey have failed to achieve the economy of scale in terms of the bank size. Probable reasons for this may be inefficient processes and the high fixed costs.

Besides the bank size and capital ratio, loan ratio and deposit ratio have also statistically significant effect on the return on asset ratio of banks in EU members. On the other hand, in Turkish banks, loan ratio and deposit ratio do not have significant effects on the return on asset ratio.

In the results of net interest margin model, all variables except deposit ratio have statistically significant effect on the results for the banks in EU members. For Turkish banks, only loan ratio and capital ratio have statistically significant effect on the net interest margin.

The main aims of the study are two folds. The first one is to investigate the internal factors which affect the bank profitability in Turkish banks. The second one is to make comparison of the banks in Turkey and EU members in terms of these profitability factors. It is thought that the study provides fruitful results for both the banks which aims to achieve sustainable profitability and the legal authorities which control the banks. 